\title{
Synergistic Interactions of Schizostatin Identified from Schizophyllum commune with Demethylation Inhibitor Fungicides
}

\author{
Min Young Park ${ }^{\mathbf{1}}$, Byeong Jun Jeon ${ }^{1}$, Ji Eun Kang ${ }^{1}$, and Beom Seok Kim ${ }^{1,2 *}$ \\ ${ }^{I}$ Department of Biosystems and Biotechnology, Korea University Graduate School, Seoul 02841, Korea \\ ${ }^{2}$ Division of Biotechnology, College of Life Sciences and Biotechnology, Korea University, Seoul 02841, Korea
}

(Received on July 29, 2020; Revised on September 27, 2020; Accepted on September 28, 2020)

Botrytis cinerea, which causes gray mold disease in more than 200 plant species, is an economically important pathogen that is mainly controlled by synthetic fungicides. Synergistic fungicide mixtures can help reduce fungicide residues in the environment and mitigate the development of fungicide-resistant strains. In this study, we screened microbial culture extracts on Botrytis cinerea to identify an antifungal synergist for tebuconazole. Among the 4,006 microbial extracts screened in this study, the culture extract from Schizophyllum commune displayed the most enhanced activity with a sub-lethal dosage of tebuconazole, and the active ingredient was identified as schizostatin. In combination with $5 \mu \mathrm{g} / \mathrm{ml}$ tebuconazole, schizostatin $(1 \mu \mathrm{g} / \mathrm{ml})$ showed disease control efficacy against gray mold on tomato leaf similar to that achieved with $20 \mu \mathrm{g} / \mathrm{ml}$ tebuconazole treatment alone. Interestingly, schizostatin showed demethylation inhibitor (DMI)-specific synergistic interactions in the crossed-paper strip assay using commercial fungicides. In a checkerboard assay with schizostatin and DMIs, the fractional inhibitory concentration values were $0.0938-0.375$. To assess the molecular mechanisms underlying this synergism, the transcription levels of the ergosterol biosynthetic genes were observed in response to DMIs, schizostatin, and their mixtures. Treatment with DMIs increased the erg11 (the target gene of DMI fungicides) expression

\footnotetext{
*Corresponding author.

Phone) +82-2-3290-3047, FAX) +82-2-921-1715

E-mail) biskim@korea.ac.kr

(c) This is an Open Access article distributed under the terms of the Creative Commons Attribution Non-Commercial License (http:// creativecommons.org/licenses/by-nc/4.0) which permits unrestricted noncommercial use, distribution, and reproduction in any medium, provided the original work is properly cited.
}

Articles can be freely viewed online at www.ppjonline.org. level 15.4-56.6-fold. However, treatment with a mixture of schizostatin and DMIs evidently reverted erg11 transcription levels to the pre-DMI treatment levels. These results show the potential of schizostatin as a natural antifungal synergist that can reduce the dose of DMIs applied in the field without compromising the disease control efficacy of the fungicides

Keywords : Botrytis cinerea, demethylation inhibitors, gray mold, schizostatin, synergistic interaction

Handling Editor : Hun Kim

Synergistic interactions of fungicides have been exploited as one of the approaches to address the adverse effects of fungicides on the environment and the development of resistant strains in a pathogen population. These synergistic mixtures of fungicides can reduce the amounts of individual active ingredients applied in the field without reducing the control efficacy, thereby delaying the development of resistant strains in a pathogen population and also allowing for the use of fungicides in accordance with the legal limits of the active ingredients (Gisi, 1996). Early studies on such synergistic interactions were performed by using combinations of commercialized fungicides. Synergistic interactions among different triazoles with identical modes of action (inhibition of $\mathrm{C} 14$ demethylation in sterol biosynthesis) were reported against Erysiphe graminis, Leptosphaeria nodorum, and Mycosphaerella graminicola in wheat (Gisi, 1996). The enhanced controlling efficacies of combinations of the systemic fungicides cymoxanil and oxadixyl and the contact fungicide mancozeb were also observed against various Phytophthora and Plasmopara species (Gisi, 1996; Gisi et al., 1985). Similarly, application of a mixture of pyrazophos and propiconazole on the barley net blotch pathogen Pyrenophora teres showed enhanced 
disease control efficacy under greenhouse conditions (Zeun and Buchenauer, 1991).

Natural products have diverse chemical structures and biological activities exceeding the capabilities of organic synthesis, in addition to showing the good biodegradability potential that is essential for environment-friendly agrochemicals (Tanaka and Omura, 1993). Considering the performance reliability of commercial fungicides, antifungal synergists of natural origin are expected to reduce the amounts of residual fungicides in the fields and mitigate resistance development. In this regard, several recent studies have shown the potential of combined treatment with natural products and commercial fungicides. The natural phenolic agent octylgallate, which targets the oxidative stress-response pathway, enhanced the activities of kresoxim-methyl and fludioxonil on Penicillium expansum (Kim et al., 2010). Similarly, the natural phenolic agent 2,3-dihydroxybenzaldehyde enhanced the activity of amphotericin B on Candida spp. (Kim et al., 2012).

Sterol demethylation inhibitors (DMIs) targeting sterol P450 14 $\alpha$-demethylase in the fungal sterol biosynthetic pathway cause deficiency of essential sterol constituents in fungal cell membranes (Joseph-Horne and Hollomon, 1997). DMI fungicides, including imidazoles and triazoles, offer several beneficial characteristics as agricultural fungicides, such as a broad antifungal spectrum and systemic distribution in plants, leading to long-lasting protection. These characteristics have resulted in extensive application of DMI fungicides in seed treatments and foliar and ear treatments. As a result, these fungicides showed the highest sales worldwide in 2013 (Kuck, 2007; Oliver and Hewitt, 2014; Ziogas and Malandrakis, 2015). However, their extensive use has resulted in the development of resistant strains and also necessitated higher application rates in the field, which can accelerate the reduction in the disease control efficacy of DMI fungicides (Holb and Schnabel, 2008). To date, most studies assessing the potential of natural products in enhancing the control efficacy of DMI fungicides evaluated the effects of plant extracts on human pathogenic yeasts. Essential oils such as eugenol, thymol, and carvacrol synergistically interacted with fluconazole by inhibiting biofilm formation and creating pores in the cell membrane, thereby increasing the penetration of antifungal agents (Doke et al., 2014; Khan and Ahmad, 2011). Diferuloylmethane (CUR-I), a major component in natural curcumin, enhanced the antifungal activities of azoles against Candida albicans by increasing the levels of reactive oxygen species and regulating the genes related to fungal oxidative stress leading to apoptosis (Sharma et al., 2010). Curcumin also acted as a specific modulator of efflux systems in Saccharomyces cerevisiae (Sharma et al., 2009). Retigeric acid B isolated from the lichen Lobaria kurokawae showed enhanced antifungal activities in combination with azole fungicides by inhibiting ergosterol biosynthesis as well as efflux pump activity (Sun et al., 2009).

Botrytis cinerea Pers. [telemorph Botryotinia fuckeliana (De Bary) Whetzel], a necrotrophic pathogen infecting more than 200 plant species, is one of the economically important plant pathogens worldwide (Jarvis, 1977). Gray mold caused by $B$. cinerea can be controlled by integrated pest management, including cultural practices and the use of resistant cultivars, and mainly by fungicide application (Fillinger and Elad, 2016). Several classes of fungicides inhibiting respiration, osmoregulation, microtubule formation, and ergosterol biosynthesis are used for control of gray mold (Leroux, 2007). Among them, the C4-demethylation inhibitor fenhexamid (commercialized in late 1990s) and DMI fungicides are the most heavily used commercial fungicides (Fillinger and Elad, 2016).

In this study, we screened microbial culture extract libraries to identify antifungal synergists of the DMI fungicide tebuconazole. The active ingredient responsible for the synergistic effect was identified through chromatographic purification procedures and spectroscopic analyses for structure elucidation. Since the active ingredient (identified to be schizostatin) showed a DMI-specific synergistic effect, we further investigated the effect of schizostatin on the expression of ergosterol biosynthesis genes in $B$. cinerea.

\section{Materials and Methods}

Fungal strains, growth conditions, and antifungal compounds. B. cinerea strain B05.10 was obtained from the VTT culture collection (http://culturecollection.vtt.fi, ref. D-071295). To prepare conidial suspension, a mycelial disc of $B$. cinerea was inoculated onto malt extract agar (Oxoid, Basingstoke, UK) plates and incubated for 2 weeks at $22^{\circ} \mathrm{C}$. The conidia were harvested by flooding the cultures with sterile distilled water or potato dextrose broth (PDB; BD Biosciences, Spark, MD, USA), rubbing the surface with a spreader, and then filtered through four sheets of Miracloth (Chicopee Mills Inc., Milltown, NJ, USA). Schizophyllum commune KUC9080 isolated from a soil of Gurye, Korea was used to construct a microbial culture extract library. The KUC9080 strain was maintained on potato dextrose agar (PDA) plates. Tebuconazole and chlorothalonil were obtained from Kyung Nong Co. Ltd (Seoul, Korea), and boscalid, dichlofluanid, fenhexamid, fludioxonil, iprodione, difenoconazole, fenarimol, fenbuconazole, fenpropimorph, imazalil, and prochloraz in this study were purchased from 
Sigma-Aldrich (St. Louis, MO, USA).

Construction of the microbial culture extract library. A microbial culture extract library used for screening a synergist of fungicides was prepared from agar cultures of fungi and actinomycetes as follows: The fungal isolate was cultured on five plates $(150 \times 20 \mathrm{~mm})$ of PDA for 14 to 20 days. The actinomycete strain was cultured on three plates $(90 \times 15 \mathrm{~mm})$ of tryptic soy agar (BD Biosciences) for 3 to 5 days. After $28^{\circ} \mathrm{C}$ incubation, the agar cultures were extracted in methanol with sonication $(120 \mathrm{~W}$ and $40 \mathrm{kHz})$. After dryness under reduced pressure at $40^{\circ} \mathrm{C}$, the residue obtained from fungi was re-suspended in distilled water $(100 \mathrm{ml})$ and partitioned with same volume of ethyl acetate. The ethyl acetate layer was concentrated in vacuo and dissolved in dimethyl sulfoxide (DMSO) at a concentration of $2 \mathrm{mg} / \mathrm{ml}$. The culture extract of actinomycetes was concentrated in vacuo and dissolved in $1 \mathrm{ml}$ of DMSO.

Selection of synergistic microbial extracts in combination with tebuconazole. Conidial suspension of $B$. cinerea B05.10 and PDB (BD Biosciences) was used for screening synergistic microbial extracts in combination with tebuconazole. The minimum inhibitory concentration (MIC) of tebuconazole for $B$. cinerea was previously determined using the two-fold broth microdilution method in three replicates (Kim et al., 2019). For screening of synergistic microbial

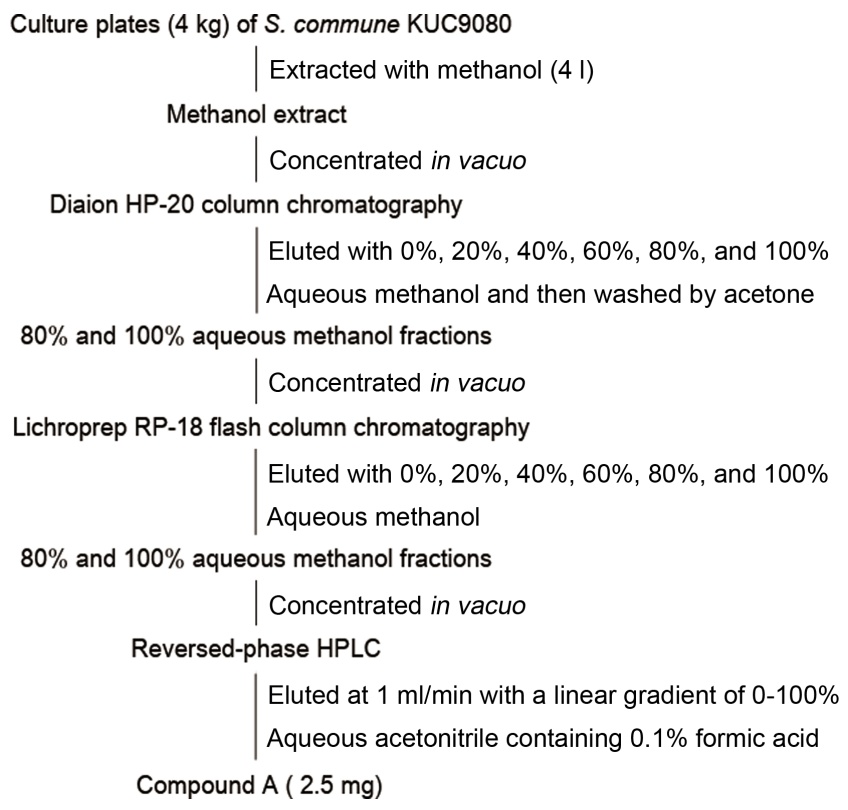

Fig. 1. Isolation scheme of compound A from the culture of Schizophyllum commune KUC9080. HPLC, high-performance liquid chromatography. extracts, $25 \mu \mathrm{l}$ of conidial suspension $\left(4 \times 10^{5}\right.$ conidia $\left./ \mathrm{ml}\right)$, $25 \mu$ of quadruple-strength PDB, $48 \mu$ of sterile water, 1 $\mu \mathrm{l}$ of microbial extract, and $1 \mu \mathrm{l}$ of tebuconazole solution $(20 \mu \mathrm{g} / \mathrm{ml}$ in DMSO) were added to each well of a 96-well plate (No. 30096, SPL Life Sciences Inc., Pocheon, Korea). The final concentration of tebuconazole in the assay mixture was one fifth of MIC. After 2 days of incubation at $22^{\circ} \mathrm{C}$, microbial extracts displaying no growth of $B$. cinerea with the sub-lethal concentration of tebuconazole were selected as potential synergists. The experiments were performed in three replicates.

Purification of the active ingredient from Schizophyllum commune KUC9080. The isolation scheme for a synergist of tebuconazole from a culture extract of $S$. commune KUC9080 was depicted in Fig. 1. The mycelial disc of $S$. commune KUC9080 was inoculated on center of the PDA plate $\left(9 \mathrm{~cm}\right.$ in diameter) and incubated for 7 days at $28^{\circ} \mathrm{C}$. The cultured agar media ( $20 \mathrm{ml}$ agar media per plate) obtained from one hundred plates were extracted with 41 of methanol. The methanol extract was evaporated under reduced pressure using a rotary evaporator (Büchi, Flawil, Switzerland) and the resulting residue was dissolved with 1 1 of $2 \%$ aqueous methanol. For synergistic activity-guided purification of the active ingredient, flash columns packed with Diaion HP-20 resin (Mitsubishi Chemical Corp., Tokyo, Japan) and LiChroprep RP-18 resin (20-63- $\mu \mathrm{m}$, Merck, Darmstadt, Germany) were subsequently used. The columns were eluted with stepwise gradients of water and methanol (100:0, 80:20, 60:40, 40:60, 20:80, and 0:100, $\mathrm{v} / \mathrm{v})$ and 11 of acetone. The active fractions obtained from each flash column chromatography were concentrated in vacuo and re-dissolved in $500 \mathrm{ml}$ of $2 \%$ aqueous methanol. The active fractions were evaporated to dryness and further purified using high performance liquid chromatography system equipped with YMC-Pack ODS-A column $(250 \times$ $4.6 \mathrm{~mm}, 5 \mu \mathrm{m}$; Tokyo, Japan). The flow rate was $1 \mathrm{ml} / \mathrm{min}$ with a $0-100 \%$ aqueous methanol gradient over $20 \mathrm{~min}$ followed by isocratic elution of $100 \%$ methanol for $20 \mathrm{~min}$. The eluents were monitored at $230 \mathrm{~nm}$ and the individual peaks were collected and tested their synergistic activity with tebuconazole. Finally, the active compound A (2.5 $\mathrm{mg}$ ) was obtained as white powder. We repeated the purification procedure to obtain enough amount of compound A for further experiments

Crossed-paper strip assay. For bioassays using crossed strips, $20 \mu \mathrm{l}$ of $25 \mu \mathrm{g} / \mathrm{ml}$ of tebuconazole and each fraction (corresponding to the extract of $2 \mathrm{ml}$ of culture broth) were loaded on each paper strip $(15 \mathrm{~mm} \times 3 \mathrm{~mm}$, no. 2 filter 
paper; Advactec, Toyo Roshi Co. Ltd., Tokyo, Japan). The strips were placed crossed perpendicularly on PDA medium seeded with $10^{5}$ conidia $/ \mathrm{ml}$ of $B$. cinerea. After 2 days of incubation, the synergistic effect of each fraction and tebuconazole was determined.

Structural elucidation of compound A. The structure of compound A isolated from a culture extract of $S$. commune KUC9080 was determined by spectroscopic data interpretation and by comparison with literature data. The electrospray ionization mass spectrometry (ESI-MS) analysis was performed using Waters Q-Tof micro mass spectrometer (Milford, MA, USA) to determine the molecular weight of compound $\mathrm{A}$. The ${ }^{1} \mathrm{H}$ - and ${ }^{13} \mathrm{C}$-nuclear magnetic resonance (NMR) spectroscopic data for compound A was recorded on Varian $500 \mathrm{MHz}$ spectrometer (Palo Alto, CA, USA) using chloroform-d (Cambridge Isotope Laboratories, Tewksbury, MA, USA). Chemical shifts were referenced to solvent peaks $\left(\delta_{\mathrm{H}} 7.26 \mathrm{ppm}\right.$ and $\left.\delta_{\mathrm{C}} 77.2 \mathrm{ppm}\right)$.

Evaluation of disease control efficacy of the schizostatintebuconazole mixture. Tomato seeds (Solanum lycopersicum L. cv. Gwangbok) were purchased from Aram Seed Co. (Seoul, Korea). Tomato plants were grown on commercial soil (Baroker, Seoul Bio Co., Ltd., Eumseong, Korea) for 4 to 6 weeks. Individually harvested leaves were placed on Advantec filter paper No. 2 (Toyo Roshi, Tokyo, Japan), and the cut petiole ends were wrapped with sterilized wet gauze to prevent dryness. Subsequently, $40 \mu 1$ of tebuconazole solution $(0,1,5,10$, and $20 \mu \mathrm{g} / \mathrm{ml})$ containing $0.05 \%(\mathrm{w} / \mathrm{v})$ Tween-20 was applied on each tomato leaf. After dryness for $1 \mathrm{~h}, 40 \mu \mathrm{l}$ of schizostatin solution $(0,0.4$, 1 , and $2.5 \mu \mathrm{g} / \mathrm{ml}$ ) containing $0.05 \%$ (w/v) Tween-20 was applied on each tomato leaf. Each solution was uniformly spread out with a brush. At $24 \mathrm{~h}$ after fungicide treatment, $B$. cinerea spores $\left(10^{6}\right.$ conidia/ml $)$ were inoculated on the two sites of a leaf in a $10 \mu \mathrm{l}$ drop. Inoculated leaves were kept in a plastic box filled with water to maintain moisture. After $25^{\circ} \mathrm{C}$ incubation in darkness for 4 days, the lesion area caused by $B$. cinerea was measured. The experiment was performed twice with three replicates of each treatment.

Examination of the synergistic spectrum of schizostatin with commercial fungicides. Synergistic interactions between schizostatin produced by Schizophyllum commune KUC9080 and commercial fungicides (boscalid, chlorothalonil, dichlofluanid, fenhexamid, fludioxonil, iprodione, tebuconazole, difenoconazole, fenarimol, fenbuconazole, fenpropimorph, imazalil, and prochloraz) were investigated using the crossed-paper strip method (Hayashi et al., 2003).
Fungicide stock solutions were prepared at a 25 -fold MIC against $B$. cinerea which determined by the broth dilution method: boscalid $(6.3 \mu \mathrm{g} / \mathrm{ml})$, chlorothalonil $(25 \mu \mathrm{g} /$ $\mathrm{ml})$, dichlofluanid $(25 \mu \mathrm{g} / \mathrm{ml})$, fenhexamid $(6.3 \mu \mathrm{g} / \mathrm{ml})$, fludioxonil $(1.6 \mu \mathrm{g} / \mathrm{ml})$, iprodione $(25 \mu \mathrm{g} / \mathrm{ml})$, tebuconazole (25 $\mu \mathrm{g} / \mathrm{ml})$, difenoconazole $(25 \mu \mathrm{g} / \mathrm{ml})$, fenarimol $(200 \mu \mathrm{g} /$ $\mathrm{ml})$, fenbuconazole $(25 \mu \mathrm{g} / \mathrm{ml})$, fenpropimorph $(100 \mu \mathrm{g} /$ $\mathrm{ml})$, imazalil $(25 \mu \mathrm{g} / \mathrm{ml})$, and prochloraz $(1.6 \mu \mathrm{g} / \mathrm{ml})$. The aliquot $(20 \mu \mathrm{l})$ of schizostatin or fungicide stock solutions was loaded onto paper strips $(15 \times 3 \mathrm{~mm}$; Advantec No. 2 filter paper) and air-dried. The strips were placed on PDA medium seeded with $10^{5}$ conidia $/ \mathrm{ml}$ of $B$. cinerea. After $22^{\circ} \mathrm{C}$ incubation for 2-4 days, the synergistic effect of schizostatin with each fungicide was observed by formation of inhibition zone around paper strips. The in vitro assessment on fungicide spectrum was conducted with three replicates.

Checkerboard assay. To quantify the synergistic interactions between schizostatin and commercial ergosterol biosynthesis inhibitors, fractional inhibitory concentration (FIC) values were examined by the checkerboard assay (De Medeiros Barbosa et al., 2016). The checkerboard assay of schizostatin combined with ergosterol biosynthesis inhibitors on $B$. cinerea was performed using 2-fold serial dilution in 96-well plates. The FIC indices were calculated as follows: $\sum \mathrm{FIC}=\mathrm{FIC}_{\mathrm{A}}+\mathrm{FIC}_{\mathrm{B}}=\left(\mathrm{C}_{\mathrm{A}} / \mathrm{MIC}_{\mathrm{A}}\right)+\left(\mathrm{C}_{\mathrm{B}} / \mathrm{MIC}_{\mathrm{B}}\right)$. The results were categorized as synergy ( $\mathrm{FIC} \leq 0.5)$, addition $(0.5<\mathrm{FIC} \leq 1)$, indifference $(1<\mathrm{FIC} \leq 4)$, or antagonism (FIC $>4)$.

Expression-level changes of sterol biosynthetic genes after treatment with schizostatin and tebuconazole (quantitative PCR, qPCR). Relative expression-level changes of erg11 (the target gene of DMIs) induced by tebuconazole/schizostatin were examined with quantitative real-time PCR (qRT-PCR) analysis. The conidia of B. cinerea $\left(200 \mu \mathrm{l}\right.$ of $10^{7}$ conidia $\left./ \mathrm{ml}\right)$ were inoculated into $20 \mathrm{ml}$ of Gamborg's B5 medium (Duchefa, Haarlem, The Netherlands) supplemented with $0.3 \%$ glucose (w/v). After $22^{\circ} \mathrm{C}$ shaking incubation for $48 \mathrm{~h}, 0.125 \mu \mathrm{g} / \mathrm{ml}$ of tebuconazole, $0.25 \mu \mathrm{g} / \mathrm{ml}$ of schizostatin, or a mixture of both compounds were added into the $B$. cinerea culture, aseptically. The treated cells were harvested 2, 4, 6, 8, 10 and 12 $\mathrm{h}$ after the treatment. Methanol was used as the negative control. Total RNA was isolated from mycelia with TRIzol reagent (Invitrogen, Carlsbad, CA, USA) in accordance with the manufacturer's instructions. First-strand cDNAs were synthesized using the iScript cDNA synthesis kit (Bio-Rad laboratories, Hercules, CA, USA) in accordance 
with the manufacturer's instructions. Real-time quantitative PCR was performed in a Bio-Rad CFX96 Real-Time PCR detection system with the SYBR Green mix (MG MED, Inc., Seoul, Korea). Amplification was performed with 39 cycles of $95^{\circ} \mathrm{C}$ for $15 \mathrm{~s}, 58^{\circ} \mathrm{C}$ for $15 \mathrm{~s}$, and $72^{\circ} \mathrm{C}$ for $15 \mathrm{~s}$. The threshold cycle values were obtained by the CFX Manager Software (version 3.1). Expression level was normalized using the levels of the housekeeping genes actin (BCIN_16g02020) and ubiquitin (BCIN_11g04470). qPCR assay was conducted with three technical replicates and two biological replicates. The primers used for PCR were designed using GenScript Real-time PCR (TaqMan) Primer Design (https://www.genscript.com/tools/real-timepcr-tagman-primer-design-tool). The transcriptional changes in erg11 (lanosterol C14 demethylase gene), the target of tebuconazole, were measured in comparison to negative control.

The changes of expression level of erg11 gene was examined after treatment of six sterol biosynthesis inhibitors $(0.125 \mu \mathrm{g} / \mathrm{ml}$ of tebuconazole, $0.0625 \mu \mathrm{g} / \mathrm{ml}$ of fenbuconazole, $0.125 \mu \mathrm{g} / \mathrm{ml}$ of difenoconazole, $0.0078 \mu \mathrm{g} / \mathrm{ml}$ of prochloraz, $1 \mu \mathrm{g} / \mathrm{ml}$ of fenpropimorph, and $0.25 \mu \mathrm{g} / \mathrm{ml}$ of fenhexamid) with or without schizostatin $(0.25 \mu \mathrm{g} / \mathrm{ml})$ on the culture of $B$. cinerea. The concentration of each ergosterol biosynthesis inhibitor (SBI) agent was based on the results of the checkerboard assay. Eight hours after the treatments, the fungal mycelia were harvested. The RNA samples were prepared using the same method mentioned previously. The transcriptional changes in the ergosterol synthetic genes, namely, erg9 (squalene synthase, BCIN_06g02400), erg7 (lanosterol synthase, BCIN_02g00670), erg11 (lanosterol C14 demethylase, BCIN_01g02780), erg24 (C14 reductase, BCIN_10g05280), and erg27 (C3 ketoreductase, BCIN_03g05110), were measured in comparison with the methanol-treated control.

Statistical analyses. Statistical analyses were performed with Statistical Analysis System version 9.2 (SAS Institute, Cary, NC, USA). For assessment of disease controlling efficacy, the least significant differences method for multiple comparisons was performed to determine differences between means. Error bars represent the standard errors of the mean of replicates of each experiment and the small letters on the bars indicate significant differences between treatments at $P<0.05$. Normalized qRT-PCR data were $\log _{2}$ transformed and subjected to $t$-tests. Asterisks in qPCR analysis show the level of significant differences between control and chemical treated cells $(P<0.05)$.

\section{Results and Discussion}

Screening of antifungal synergists for tebuconazole from microbial extracts. In order to screen the microbial extracts displaying synergistic effects with tebuconazole, the MIC of tebuconazole for $B$. cinerea $\left(1 \times 10^{6}\right.$ conidia/ $\mathrm{ml}$ ) under the assay conditions was first determined, and was found to be $1 \mu \mathrm{g} / \mathrm{ml}$. Next, each well of 96-well plates was dispensed with a sub-lethal dose of tebuconazole (one fifth of the MIC), conidial suspension of $B$. cinerea, and a microbial extract. After 2 days of incubation at $22^{\circ} \mathrm{C}$, when the mycelia filled the wells of the negative control (conidial suspension and DMSO), the microbial extracts displaying growth inhibition of $B$. cinerea with the $1 / 5 \mathrm{MIC}$ tebuconazole were selected as candidate antifungal synergists of tebuconazole. The microbial extracts showing complete inhibition of mycelial growth in the absence of tebuconazole were further diluted and re-examined for their synergistic effect with tebuconazole.

Among the 4,006 microbial extracts, 62 extracts (17 fungal extracts and 45 actinomycete extracts) showed synergistic effects (Supplementary Table 1). We re-examined the synergistic effects of these 62 microbial extracts by using crossed-paper strip assays with a sub-lethal dose of tebuconazole $(0.5 \mu \mathrm{g}$ per paper strip, $15 \mathrm{~mm} \times 3 \mathrm{~mm})$ and 40 $\mu \mathrm{l}$ of microbial extract (corresponding to the extract of $2 \mathrm{ml}$ of culture broth). The extract of Schizophyllum commune strain KUC9080 generated the largest inhibition zone in the center of the crossed-paper strips. Therefore, the KUC9080 strain was selected for further studies to identify active ingredients exerting the synergistic effect.

Identification of the active ingredient for the synergistic effect. The Diaion HP-20 column chromatography produced an $80-100 \%$ methanol eluate with synergistic effects, which was further chromatographed on C18 resin. The active fraction ( $80-100 \%$ methanol eluate) from $\mathrm{C} 18$ column chromatography was subjected to reverse-phase high-performance liquid chromatography (HPLC) system and eluted with a linear gradient mobile phase of $0-100 \%$ acetonitrile supplemented with formic acid. The major peak detected at the retention time of 18.5 min showed a synergistic effect in the crossed-paper strip assay. The active peak eluate was collected through a repeated preparative HPLC procedure and lyophilized to white powder (2.5 $\mathrm{mg}$ ). The purification procedures were repeated to obtain enough white powder (denoted as compound A), which was subjected to spectroscopic analyses.

The ESI-MS data for compound A showed the pseu- 
$(+)$
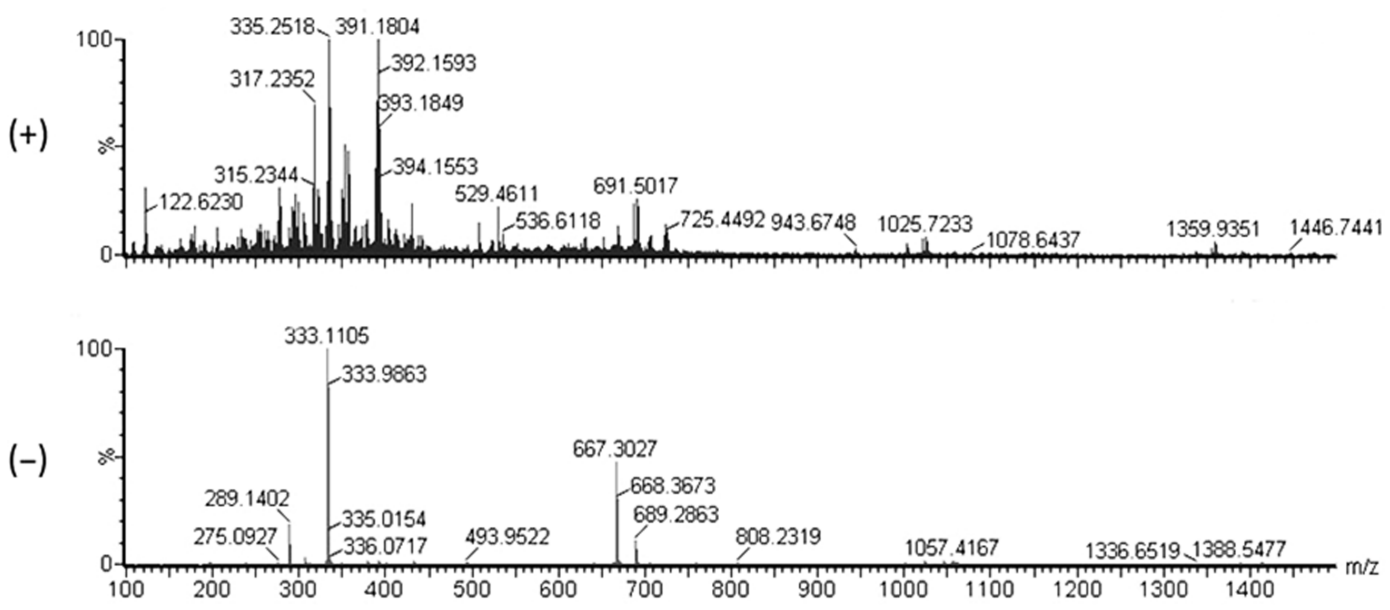

Fig. 2. The electrospray ionization mass spectrometry data for compound $A$. The pseudo-molecular ions at $\mathrm{m} / \mathrm{z} 335[\mathrm{M}+\mathrm{H}]^{+}$and $333[\mathrm{M}$ $-\mathrm{H}]^{-}$were observed in the positive- (upper) and negative (lower) ion modes, respectively.

domolecular ions at $\mathrm{m} / \mathrm{z} 335[\mathrm{M}+\mathrm{H}]^{+}$and $333[\mathrm{M}-\mathrm{H}]^{-}$, corresponding a molecular weight of $334 \mathrm{Da}$ (Fig. 2). The molecular formula of compound $\mathrm{A}$ was deduced to be $\mathrm{C}_{20} \mathrm{H}_{30} \mathrm{O}_{4}$. The NMR spectroscopic data of compound $\mathrm{A}$ are shown in Table 1 . The ${ }^{13} \mathrm{C}$-NMR spectrum of compound A showed 20 carbon signals consisting of two carbonyl $\left(\delta_{\mathrm{C}} 170.8\right.$ and 169.3$)$, four quaternary $\mathrm{sp}^{2}\left(\delta_{\mathrm{C}} 148.9,137.1\right.$,
135.2, and 131.5), four methine $\operatorname{sp}^{2}\left(\delta_{\mathrm{C}} 127.3,124.5,124.2\right.$, and 122.6), six methylene $\mathrm{sp}^{2}\left(\delta_{\mathrm{C}} 39.9,39.7,27.9,27.6\right.$, 26.8, and 26.6), and four methyl groups $\left(\delta_{\mathrm{C}} 25.9,17.8,16.1\right.$, and 16.1). The ${ }^{1} \mathrm{H}-\mathrm{NMR}$ spectrum of compound A showed signals for four methine $\left(\delta_{\mathrm{H}} 6.88,5.18,5.09\right.$, and 5.09), six methylene $\left(\delta_{\mathrm{H}} 2.85,2.22,2.05,2.05,1.97,1.97\right)$, and four singlet methyl protons $\left(\delta_{\mathrm{H}} 1.67,1.60,1.59,1.59\right)$. By com-

Table $1 .{ }^{13} \mathrm{C}(125 \mathrm{MHz})$ and ${ }^{1} \mathrm{H}(500 \mathrm{MHz})$ NMR spectra of compound A in chloroform-d

\begin{tabular}{|c|c|c|c|c|}
\hline \multirow{2}{*}{ Carbon no. } & \multicolumn{2}{|c|}{ Compound A } & \multicolumn{2}{|c|}{ Schizostatin $^{\mathrm{a}}$} \\
\hline & $\delta_{\mathrm{C}}$, Type & $\delta_{\mathrm{H}}$, mult. $(J$ in $\mathrm{Hz})$ & $\delta_{\mathrm{C}}$, Type & $\delta_{\mathrm{H}}$, mult. $(J$ in $\mathrm{Hz})$ \\
\hline 1 & $169.3, \mathrm{C}$ & - & $171.0, \mathrm{C}$ & - \\
\hline 2 & $127.3, \mathrm{CH}$ & $6.88, \mathrm{~s}$ & $127.6, \mathrm{CH}$ & $6.90, \mathrm{~s}$ \\
\hline 3 & $148.9, \mathrm{C}$ & - & 149.1, C & - \\
\hline 4 & $28.1, \mathrm{CH}_{2}$ & $2.85, \mathrm{t}(7.5)$ & 27.9, $\mathrm{CH}_{2}$ & $2.86, \mathrm{t}, 7.5$ \\
\hline 5 & $27.7, \mathrm{CH}_{2}$ & $2.22, \mathrm{dd}(7.4,14.8)$ & 27.6, $\mathrm{CH}_{2}$ & $2.23, \mathrm{q}, 7.5$ \\
\hline 6 & $122.6, \mathrm{CH}$ & $5.18, \mathrm{t}(7.1)$ & $122.5, \mathrm{CH}$ & $5.19, \mathrm{t}$ \\
\hline 7 & 137.1, C & - & 137.0, C & - \\
\hline 7-Me & $16.1, \mathrm{CH}_{3}$ & $1.60, \mathrm{~s}$ & $15.9, \mathrm{CH}_{3}$ & $1.61, \mathrm{~s}$ \\
\hline 8 & $39.85, \mathrm{CH}_{2}$ & $1.97, \mathrm{dd}(6.0,13.9)$ & 39.7, $\mathrm{CH}_{2}$ & $1.98, \mathrm{q}, 7.5$ \\
\hline 9 & 26.7, $\mathrm{CH}_{2}$ & $2.05, \mathrm{dd}(6.5,13.2)$ & 26.6, $\mathrm{CH}_{2}$ & $2.06, \mathrm{q}, 7.5$ \\
\hline 10 & $124.2, \mathrm{CH}$ & $5.09, \mathrm{~m}$ & $124.1, \mathrm{CH}$ & $5.10, \mathrm{t}$ \\
\hline 11 & $135.2, \mathrm{C}$ & - & $135.1, \mathrm{C}$ & - \\
\hline 11-Me & $16.1, \mathrm{CH}_{3}$ & $1.59, \mathrm{~s}$ & $16.0, \mathrm{CH}_{3}$ & $1.59, \mathrm{~s}$ \\
\hline 12 & $39.8, \mathrm{CH}_{2}$ & $1.97, \mathrm{dd}(6.0,13.9)$ & 39.7, $\mathrm{CH}_{2}$ & $1.97, \mathrm{q}, 7.5$ \\
\hline 13 & $26.9, \mathrm{CH}_{2}$ & $2.05, \mathrm{dd}(6.5,13.2)$ & $26.8, \mathrm{CH}_{2}$ & $2.05, \mathrm{q}, 7.5$ \\
\hline 14 & $124.5, \mathrm{CH}$ & $5.09, \mathrm{~m}$ & $124.4, \mathrm{CH}$ & $5.09, \mathrm{t}$ \\
\hline 15 & $131.5, \mathrm{C}$ & - & $131.2, \mathrm{C}$ & - \\
\hline 15-Me & $17.8, \mathrm{CH}_{3}$ & $1.59, \mathrm{~s}$ & 17.7, $\mathrm{CH}_{3}$ & $1.59, \mathrm{~s}$ \\
\hline 16 & $25.9, \mathrm{CH}_{3}$ & $1.67, \mathrm{~s}$ & $25.7, \mathrm{CH}_{3}$ & $2.00, \mathrm{~s}$ \\
\hline 17 & $170.8, \mathrm{C}$ & - & $172.3, \mathrm{C}$ & - \\
\hline
\end{tabular}

${ }^{a}$ The previously reported nuclear magnetic resonance (NMR) data of schizostatin (Kogen et al., 1996). 


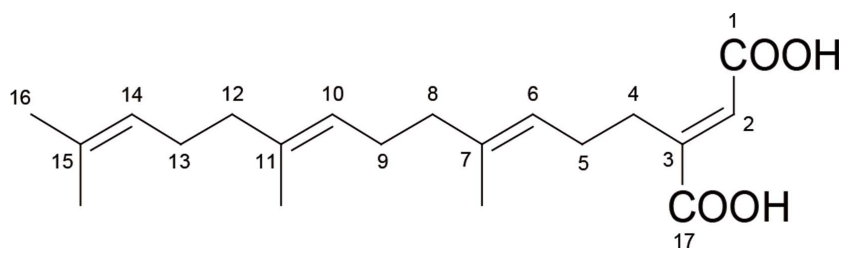

Fig. 3. Structure of compound A (schizostatin) from Schizophyllum commune KUC9080.

parison with the previously reported NMR data (Kogen et al., 1996), the compound A was identified as schizostatin (Fig. 3).

Synergistic spectrum of schizostatin on commercial fungicides. To quantify the amount of schizostatin exerting synergistic effects with tebuconazole, we measured the respective FIC indices using broth microdilution assays (Table 2, Supplementary Fig. 1). The MIC values of tebuconazole and schizostatin against $B$. cinerea were 1 and $4 \mu \mathrm{g} / \mathrm{ml}$, respectively. In the checkerboard assay, the combination of tebuconazole and schizostatin yielded a significant decrease in their respective MIC values. At the most effective combination of these two compounds, 0.125 $\mu \mathrm{g} / \mathrm{ml}$ of tebuconazole (1/8 of the MIC of tebuconazole alone) and $0.25 \mu \mathrm{g} / \mathrm{ml}$ of schizostatin (1/16 of the MIC of schizostatin alone) inhibited the growth of $B$. cinerea with the lowest FIC index value of 0.1875 . Since the synergistic effect of schizostatin with tebuconazole was obvious in in vitro and in vivo assays, we examined the spectrum of this synergistic effect by performing crossed-paper strip assays using other commercial fungicides with schizostatin. For this experiment, sub-lethal doses of several commercial fungicides were first determined. Schizostatin $(2 \mu \mathrm{g})$ was loaded on a paper strip, and $20 \mu \mathrm{l}$ of $25 \times$ MIC stock solutions of seven fungicides, namely, boscalid $(0.125 \mu \mathrm{g}$ per paper strip), chlorothalonil ( $0.5 \mu \mathrm{g}$ per paper strip), dichlofluanid (0.5 $\mu \mathrm{g}$ per paper strip), fenhexamid (0.125 $\mu \mathrm{g}$ per paper strip), fludioxonil (0.031 $\mu \mathrm{g}$ per paper strip), iprodione $(0.5 \mu \mathrm{g}$ per paper strip), and tebuconazole $(0.5 \mu \mathrm{g}$ per paper strip) were loaded on another paper strip. Methanol was loaded on horizontal strips as a negative control. When paper strips impregnated with schizostatin and tebuconazole were placed perpendicularly on a medium seeded with $B$. cinerea, a clear inhibition zone was generated at the junction of the two crossed strips. However, schizostatin did not generate inhibition zones in combination with the other commercial fungicides (boscalid, chlorothalonil, dichlofluanid, fludioxonil, iprodione and fenhexamid). We were curious if the antifungal synergistic effect of schizostatin is limited to tebuconazole or extends to other C14-demethylation inhibitors (DMIs) or SBIs. In the assay with four DMIs - difenoconazole $(0.5 \mu \mathrm{g})$, fenarimol (4

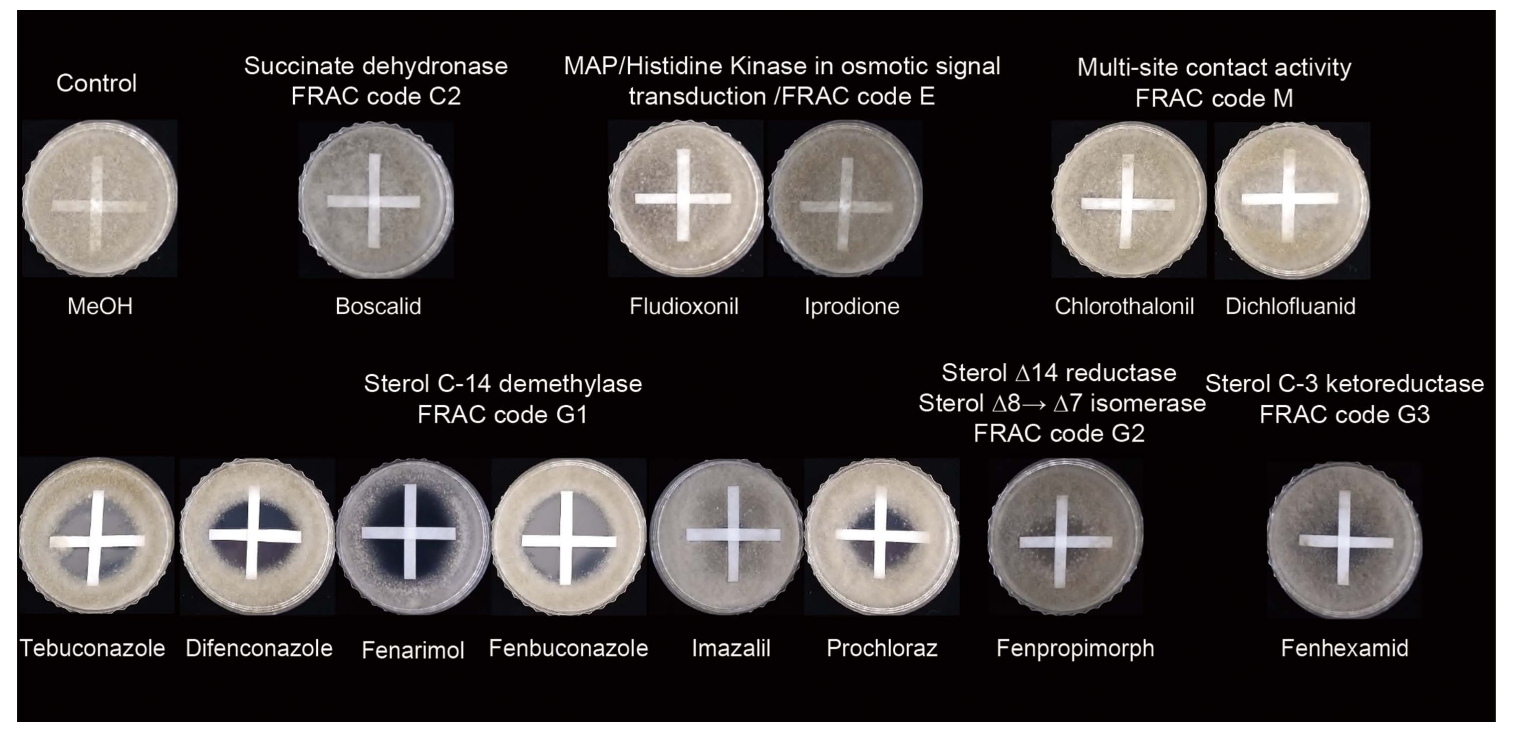

Fig. 4. Synergistic effect of schizostatin with thirteen fungicides against Botrytis cinerea was tested by the cross-strip method. Schizostatin $(2 \mu \mathrm{g})$ was loaded on the vertical strips and $20 \mu \mathrm{l}$ of fungicide stock solutions were loaded on the horizontal strips. Fungicide stock solutions were prepared at a 25 -fold minimum inhibitory concentration which determined by the broth dilution method: boscalid $(6.25 \mu \mathrm{g} / \mathrm{ml})$, chlorothalonil $(25 \mu \mathrm{g} / \mathrm{ml})$, dichlofluanid $(25 \mu \mathrm{g} / \mathrm{ml})$, fenhexamid $(6.25 \mu \mathrm{g} / \mathrm{ml})$, fludioxonil $(1.56 \mu \mathrm{g} / \mathrm{ml}), \mathrm{iprodione}(25 \mu \mathrm{g} /$ $\mathrm{ml})$, tebuconazole $(25 \mu \mathrm{g} / \mathrm{ml})$, difenoconazole $(25 \mu \mathrm{g} / \mathrm{ml})$, fenarimol $(200 \mu \mathrm{g} / \mathrm{ml})$, fenbuconazole $(25 \mu \mathrm{g} / \mathrm{ml})$, fenpropimorph $(100 \mu \mathrm{g} /$ $\mathrm{ml})$, imazalil $(25 \mu \mathrm{g} / \mathrm{ml})$, and prochloraz $(1.56 \mu \mathrm{g} / \mathrm{ml})$. Fungicides were sorted by mode of action (including FRAC code numbering). Methanol was used as a negative control. 

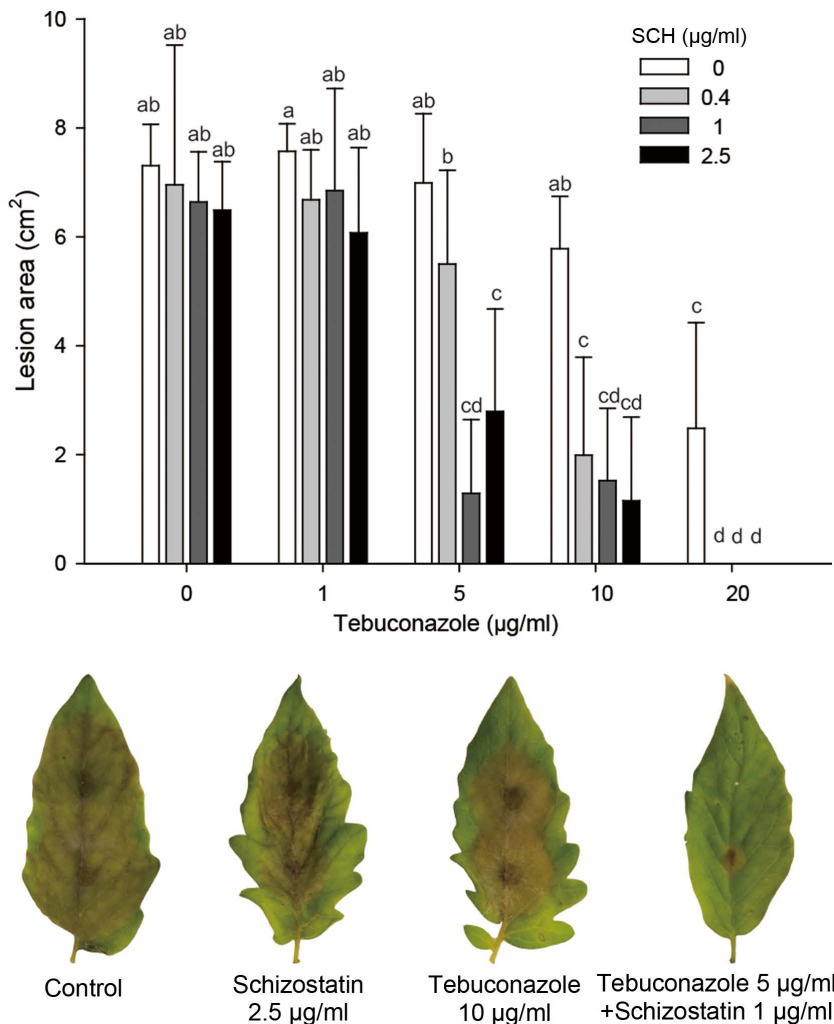

Fig. 5. In vivo control efficacy of co-treatment with tebuconazole and schizostatin against gray mold. A conidial suspension $\left(10^{6}\right.$ conidia/ml) of Botrytis cinerea was used as an inoculum. Tebuconazole and schizostatin were treated 1 day before inoculation. After 4 days, the necrotic lesion area was measured. Error bars represent the standard errors of the mean of six replicates. $\mathrm{SCH}$, schizostatin. Small letters on the bars indicate significant differences between treatments at $P<0.05$.

$\mu \mathrm{g})$, fenbuconazole $(0.5 \mu \mathrm{g})$ and prochloraz $(0.031 \mu \mathrm{g})$ at sub-lethal doses, clear zones of inhibition were observed at the center of the stripes crossed with schizostatin, implying that schizostatin can exert antifungal synergistic effects in combination with other DMIs as well (Fig. 4). The sizes of the inhibition zones generated by combinations with other DMIs were comparable to those generated with tebuconazole. However, other non-DMI SBIs such as fenpropimorph $(2 \mu \mathrm{g})$, which targets $\mathrm{C} 14$ reductase (erg24), showed weak synergistic activity with schizostatin (Fig. 5). Fenhexamid $(0.125 \mu \mathrm{g})$, which inhibits $\mathrm{C} 3$ ketoreductase (erg27) in the ergosterol biosynthesis pathway, showed no interaction with schizostatin.

To quantify the synergistic effects of schizostatin and SBIs, we measured the respective FIC indices using the broth microdilution assay (Table 2). The FIC index values for the five DMI fungicides (fenbuconazole, difenoconazole, imazalil, prochloraz, and fenarimol) in combination with schizostatin were $0.0938-0.375$, all below the value of 0.5 . The FIC index value for fenpropimorph with schizostatin was 0.375 and that for fenhexamid with schizostatin was higher than 1 , indicating that there was no interaction between fenhexamid and schizostatin.

The results of assays to determine the synergistic spectrum of purified schizostatin with commercial fungicides showed DMI-specific enhancement. Schizostatin enhanced the antifungal efficacies of ergosterol synthesis inhibitors, especially DMIs. These results suggest that the synergistic interaction may result from targeting different steps in the sterol biosynthetic pathway. Similar to our findings, terbinafine, a non-cytochrome P450 squalene epoxidase inhibitor, enhanced the antifungal activity of azole fungicides by accumulation of intracellular squalene and disruption of the fungal cell membrane (Meletiadis et al., 2003; Perea et al., 2002). The FIC values between terbinafine and azoles ranged from 0.25 to 2 depending on the Candida isolates.

Table 2. MICs and FICs of SBIs and schizostatin against Botrytis cinerea

\begin{tabular}{lllll}
\hline Fungicide & Target site & MIC $(\mu \mathrm{g} / \mathrm{ml})$ & FIC $^{\text {index }}{ }^{\mathrm{a}}$ & Interpretation $^{\mathrm{b}}$ \\
\hline Difenoconazole & Sterol C-14 demethylase & 1 & 0.125 & Synergy \\
Fenarimol & & 8 & 0.1875 & Synergy \\
Fenbuconazole & & 1 & 0.0938 & Synergy \\
Imazalil & & 1 & 0.375 & Weak synergy \\
Prochloraz & & 0.0625 & 0.1875 & Synergy \\
Tebuconazole & & 1 & 0.1875 & Synergy \\
Fenpropimorph & Sterol $\Delta^{14}$ reductase and sterol $\Delta^{8} \rightarrow \Delta^{7}$-isomerase & 4 & 0.375 & Weak synergy \\
Fenhexamid & Sterol C3-keto reductase & 0.25 & 2.5 & Indifference \\
Schizostatin & Squalene synthase & 4 & - & - \\
\hline
\end{tabular}

MIC, minimum inhibitory concentration; FIC, fractional inhibitory concentration; SBI, ergosterol biosynthesis inhibitor. ${ }^{\mathrm{a}} \mathrm{FIC}$ index was calculated as FIC $=(\mathrm{MIC}$ of SBI + schizostatin $) /(\mathrm{MIC}$ of SBI $)+(\mathrm{MIC}$ of schizostatin $+\mathrm{SBI}) /(\mathrm{MIC}$ of schizostatin $)$. ${ }^{\mathrm{b}} \mathrm{FIC} \leq 0.5$, synergy; $0.5<$ FIC $\leq 1.0$, addition; $1.0 \leq \mathrm{FIC}<4$, indifference; FIC $\geq 4$, antagonism. 
Similarly, statins, competitive inhibitors of HMG-CoA reductase were reported to show synergistic effects with azoles against Candida spp. Fluvastatin in combination with fluconazole and ketoconazole showed synergistic interactions against $C$. albicans and Aspergillus flavus and simvastatin in combination with miconazole showed enhanced activity against $C$. glabrata (Nyilasi et al., 2010). In our study, schizostatin significantly enhanced the antifungal activities of DMI fungicides, including azoles, fenarimol, and imidazoles. Additionally, schizostatin showed a weak synergistic interaction with morpholine and no interaction with fenhexamid. These various patterns of interactions between schizostatin and DMIs suggest that the synergism cannot simply be attributed to an additive effect of both compounds on membrane disruption followed by penetration of the fungicides.

Effects of schizostatin and tebuconazole mixtures on gray mold development. The effects of combined tebuconazole and schizostatin treatment were evaluated on tomato leaves infected with $B$. cinerea in comparison to the effects of individual treatments with the two compounds (Fig. 5). The control efficacy was evaluated by measuring the lesion area expanding beyond the inoculation spot on the leaves. Individual treatment with schizostatin showed no significant control effect at all concentrations tested (highest concentration, $2.5 \mu \mathrm{g} / \mathrm{ml}$ ). Tebuconazole treatment at 1,5 , and $10 \mu \mathrm{g} / \mathrm{ml}$ also did not cause any difference in the lesion area in comparison with non-treated control, while treatment with $20 \mu \mathrm{g} / \mathrm{ml}$ resulted in evident control efficacy. However, a mixture of $5 \mu \mathrm{g} / \mathrm{ml}$ tebuconazole and $0.4 \mu \mathrm{g} / \mathrm{ml}$ schizostatin significantly reduced the lesion area on the leaf in comparison to the lesion area on nontreated leaves. Treatments with $5 \mu \mathrm{g} / \mathrm{ml}$ tebuconazole and increased amounts of schizostatin ( 1 or $2.5 \mu \mathrm{g} / \mathrm{ml}$ ) resulted in further reductions of the lesion area that were comparable to those achieved with individual treatment using 20 $\mu \mathrm{g} / \mathrm{ml}$ tebuconazole. When the concentration of tebuconazole was increased to $10 \mu \mathrm{g} / \mathrm{ml}$, supplementation of 0.4 $\mu \mathrm{g} / \mathrm{ml}$ schizostatin yielded similar control efficacy to that achieved with individual treatment using $20 \mu \mathrm{g} / \mathrm{ml}$ tebuconazole.

The antifungal activity of schizostatin, previously reported to be a potent squalene synthase inhibitor (Tanimoto et al., 1996), was demonstrated against plant pathogenic fungi by Dutta et al. (Dutta et al., 2019). In that report, schizostatin showed modest antifungal activity against $B$. cinerea. and its control effect of schizostatin on gray mold development was observed on detached pepper fruit treated with more than $50 \mu \mathrm{g} / \mathrm{ml}$. The control efficacy of schizostatin in that study was $83.2 \%$ and $94.6 \%$ after treatment at concentrations of $100 \mu \mathrm{g} / \mathrm{ml}$ and $150 \mu \mathrm{g} / \mathrm{ml}$, respectively. This modest control efficacy on gray mold was also observed in our study. However, schizostatin showed an evident synergistic effect with tebuconazole in the control of gray mold development on detached tomato leaves. At the highest concentration of tebuconazole (20 $\mu \mathrm{g} / \mathrm{ml}$ ) used in this study, the gray mold lesion area was limited to $2.48 \mathrm{~cm}^{2}$, while the lesion area in the non-treated control was $7.31 \mathrm{~cm}^{2}$. However, in combination with 0.4 $\mu \mathrm{g} / \mathrm{ml}$ schizostatin, $20 \mu \mathrm{g} / \mathrm{ml}$ tebuconazole completely prevented lesion progression. The synergistic effect of schizostatin was also evident at lower tebuconazole concentrations. Treatment with $5 \mu \mathrm{g} / \mathrm{ml}$ tebuconazole and 1 $\mu \mathrm{g} / \mathrm{ml}$ schizostatin showed a significant control effect on gray mold while individual treatments with the compounds at 5 and $1 \mu \mathrm{g} / \mathrm{ml}$, respectively, did not result in any significant effect on gray mold development.

Transcriptional changes in the ergosterol biosynthetic genes of $B$. cinerea treated with mixtures of schizostatin and SBIs. In order to estimate the molecular mechanisms underlying this synergism, the transcription levels of the ergosterol biosynthetic genes were observed in response to DMIs, schizostatin, and mixtures of both. The transcriptional changes in erg11 (lanosterol demethylase gene) were measured 2, 4, 6, 8, 10, and $12 \mathrm{~h}$ after tebuconazole treatment (Supplementary Fig. 2). The transcript levels of erg11 began to increase at $4 \mathrm{~h}$ and increased 29.8-fold by $8 \mathrm{~h}$ after tebuconazole treatment ( $1 / 8 \mathrm{MIC}: 0.125 \mu \mathrm{g} / \mathrm{ml})$ while no significant changes in erg 11 transcript levels were observed after methanol treatment (negative control). However, on treatment with tebuconazole (1/8 MIC) supplemented with schizostatin (1/16 MIC), this increase in erg11 transcript levels was not observed; thus, the transcript levels until $8 \mathrm{~h}$ showed no difference from those observed in the negative control.

We were curious to determine whether this effect of schizostatin supplementation on the increased transcription level of target genes would be observed with the other SBIs. Six SBIs (tebuconazole, fenbuconazole, difenoconazole, prochloraz, fenpropimorph, fenhexamid) were applied onto $B$. cinerea mycelium with or without schizostatin. The SBI concentrations used for this treatment were the lowest concentrations displaying synergistic inhibition of $B$. cinerea in the checkerboard assay with 0.25 $\mu \mathrm{g} / \mathrm{ml}$ schizostatin. In the checkerboard assay, tebuconazole showed the highest synergistic effect with the lowest FIC value (0.1875) at a schizostatin concentration of 0.25 $\mu \mathrm{g} / \mathrm{ml}$ and tebuconazole concentration of $0.125 \mu \mathrm{g} / \mathrm{ml}$. The 

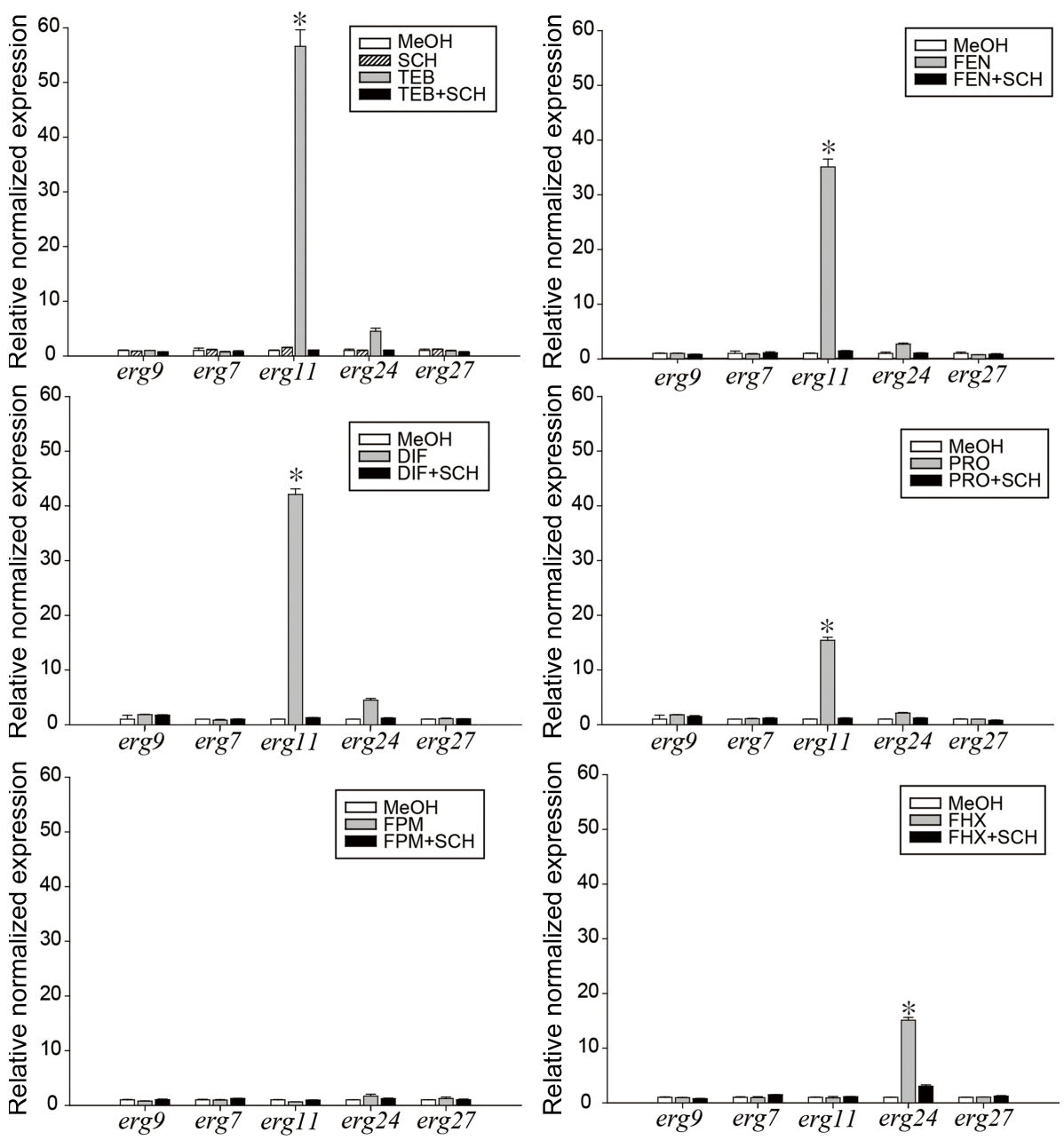

Fig. 6. Relative expression of genes involved in the ergosterol biosynthesis pathway in Botrytis cinerea. The expression of the erg9 (squalene synthase), $\operatorname{erg} 7$ (lanosterol synthase), erg11 (lanosterol demethylase), erg24 (sterol C-14 reductase), and erg27 (sterol C-3 ketoreductase) genes in response to incubation with ergosterol biosynthesis inhibitors and $\mathrm{SCH}$ was investigated using reverse-transcription $\mathrm{PCR}$ and real-time $\mathrm{PCR}$ in $B$. cinerea. $\mathrm{SCH}$, schizostatin; TEB, tebuconazole; FEN, fenbuconazole; DIF, difenconazole; PRO, prochloraz; FPM, fenpropimorph; FHX, fenhexamid. Methanol $(\mathrm{MeOH})$ was used as a negative control. Asterisks indicate statistically significant differences $(* P<0.05)$.

other five SBIs, except fenhexamid, showed reduced MICs in combination with $0.25 \mu \mathrm{g} / \mathrm{ml}$ schizostatin. For this reason, the concentrations of these five SBIs were the lowest concentrations showing synergistic inhibition of $B$. cinerea with $0.25 \mu \mathrm{g} / \mathrm{ml}$ schizostatin in the checkerboard assay. Fenhexamid was used at its MIC value. The transcription levels of five ergosterol biosynthetic genes (erg9, erg7, erg11, erg24, and erg27) were analyzed by qRT-PCR at $8 \mathrm{~h}$ after the treatments (Fig. 6). Schizostatin alone did not induce any significant changes in the transcript levels of the ergosterol biosynthetic genes examined in this study. After treatment with tebuconazole, the transcript level of erg11, whose gene product is the target of DMIs, significantly increased up to 56.6-fold while those of the other genes remained unchanged. In contrast, after mixed treatment with tebuconazole and schizostatin, the transcript levels of erg11 and the other genes did not show an increase. Similarly, while the expression level of erg11 increased 35.1-, 42.1-, and 15.4-fold, respectively, after treatment with fenbuconazole, difenoconazole, and prochloraz, when these DMI treatments were accompanied with schizostatin, the erg11 expression level returned to the level of the negative control. Treatment with fenpropimorph did not result in significant changes in the expression levels of the five genes examined, and the basal levels were maintained after treatment with fenpropimorph alone and in combination with schizostatin. Fenhexamid increased the erg24 transcript level by up to 15.3 -fold and mixed treatment with schizostatin decreased it to non-significant levels.

In the RNA sequencing analyses, $\operatorname{erg} 11$ was the most upregulated by tebuconazole (data not shown), and this result is in agreement with previous studies in which azole fungicides inhibited erg11 (lanosterol C14 demethylase) gene products in the sterol biosynthetic pathway and the expression level of $\operatorname{erg} 11$ gene was elevated to modulate ergosterol levels (Liu et al., 2010; Rogers and Barker, 2003). The upregulation of erg genes in response to azoles was suggested to be initiated by depletion of a late product (e.g., ergosterol) of the pathway or the accumulation of early substrates or toxic sterol byproduct (Henry et al., 2000). 
In our study, treatment with schizostatin (1/16 MIC) along with DMIs reverted the $\operatorname{erg} 11$ upregulation induced by the four DMI fungicides, while treatment with schizostatin alone did not result in significant changes in the expression of the five $e r g$ genes.

Citral, a constituent of plant essential oils, has been reported to show antifungal activity against Penicillium digitatum via downregulation of the expression levels of five erg genes (erg7, erg11, erg6, erg3, and erg5) (OuYang et al., 2016). Eugenol and its analogues enhanced the activity of fluconazole by inhibition of ergosterol biosynthesis and resulted in downregulation of ergl1 at their respective MICs (Ahmad et al., 2015). Retigeric acid B enhanced the antifungal activity of azoles and also downregulated erg11 expression ( 0.45 -fold compared to untreated group) and decreased the ergosterol level by $46.6 \%$ at its MIC, resulting in increased membrane fluidity and diffusion of antifungals in C. albicans (Sun et al., 2009). In previous studies, fenhexamid did not change the expression levels of general erg genes including erg27 (known as the target of fenhexamid) in S. cerevisiae (Kagan et al., 2005). In our study, however, after treatment with fenhexamid, the expression of $\operatorname{erg} 24$, the preceding step mediated by the erg27 product, increased 15.1-fold, and schizostatin reverted the gene expression to the control level.

In conclusion, we found that the fungal metabolite schizostatin had synergistic effects with DMI fungicides against $B$. cinerea. The combined application of schizostatin with DMI fungicides can effectively control gray mold in tomato and showed better control efficacy than individual treatments with the fungicides. We also confirmed that this synergistic activity is specific to DMI fungicides, suggesting that one possible mechanism of this synergism is downregulation of ergll gene expression. This approach to identify natural products showing synergistic effects with commercial fungicides could be helpful in enhancing the efficiency of commercial fungicides while minimizing fungicide exposure in the environment.

\section{Conflicts of Interest}

No potential conflict of interest relevant to this article was reported.

\section{Acknowledgments}

This work was supported by the National Research Foundation of Korea (NRF) grant funded by the Korea Government (NRF-2014R1A2A2A01005461).

\section{Electronic Supplementary Material}

Supplementary materials are available at The Plant Pathology Journal website (http://www.ppjonline.org/).

\section{References}

Ahmad, A., Wani, M. Y., Khan, A., Manzoor, N. and Molepo, J. 2015. Synergistic interactions of eugenol-tosylate and its congeners with fluconazole against Candida albicans. PLoS ONE 10:e145053.

De Medeiros Barbosa, I., da Costa Medeiros, J. A., de Oliveira, K. Á. R., Gomes-Neto, N. J., Tavares, J. F., Magnani, M. and de Souza, E. L. 2016. Efficacy of the combined application of oregano and rosemary essential oils for the control of Escherichia coli, Listeria monocytogenes and Salmonella Enteritidis in leafy vegetables. Food Control 59:468-477.

Doke, S. K., Raut, J. S., Dhawale, S. and Karuppayil, S. M. 2014. Sensitization of Candida albicans biofilms to fluconazole by terpenoids of plant origin. J. Gen. Appl. Microbiol. 60:163168.

Dutta, S., Woo, E.-E., Yu, S.-M., Nagendran, R., Yun, B.-S. and Lee, Y. H. 2019. Control of anthracnose and gray mold in pepper plants using culture extract of white-rot fungus and active compound schizostatin. Mycobiology 47:87-96.

Fillinger, S. and Elad, Y. 2016. Botrytis: the fungus, the pathogen and its management in agricultural systems. Springer International Publishing, Cham, Switzerland. 486 pp.

Gisi, U. 1996. Synergistic interaction of fungicides in mixtures. Phytopathology 86:1273-1279.

Gisi, U., Binder, H. and Rimbach, E. 1985. Synergistic interactions of fungicides with different modes of action. Trans. $B$ r. Mycol. Soc. 85:299-306.

Hayashi, K., Schoonbeek, H.-J. and De Waard, M. A. 2003. Modulators of membrane drug transporters potentiate the activity of the DMI fungicide oxpoconazole against Botrytis cinerea. Pest Manag. Sci. 59:294-302.

Henry, K. W., Nickels, J. T. and Edlind, T. D. 2000. Upregulation of ERG genes in Candida species by azoles and other sterol biosynthesis inhibitors. Antimicrob. Agents Chemother. 44:2693-2700.

Holb, I. J. and Schnabel, G. 2008. The benefits of combining elemental sulfur with a DMI fungicide to control Monilinia fructicola isolates resistant to propiconazole. Pest Manag. Sci. 64:156-164.

Jarvis, W. R. 1977. Botryotinia and Botrytis species: taxonomy, physiology and pathogenicity: a guide to the literature. Canada Department of Agriculture, Ottawa, Canada. 206 pp.

Joseph-Horne, T. and Hollomon, D. W. 1997. Molecular mechanisms of azole resistance in fungi. FEMS Microbiol. Lett. 149:141-149.

Kagan, I. A., Michel, A., Prause, A., Scheffler, B. E., Pace, P. and Duke, S. O. 2005. Gene transcription profiles of Saccharomy- 
ces cerevisiae after treatment with plant protection fungicides that inhibit ergosterol biosynthesis. Pestic. Biochem. Physiol. 82:133-153.

Khan, M. S. A. and Ahmad, I. 2011. Antifungal activity of essential oils and their synergy with fluconazole against drugresistant strains of Aspergillus fumigatus and Trichophyton rubrum. Appl. Microbiol. Biotechnol. 90:1083-1094.

Kim, J. D., Park, M. Y., Jeon, B. J. and Kim, B. S. 2019. Disease control efficacy of 32,33-didehydroroflamycoin produced by Streptomyces rectiviolaceus strain DY46 against gray mold of tomato fruit. Sci. Rep. 9:13533.

Kim, J. H., Faria, N. C. G., Martins, M. D. L., Chan, K. L. and Campbell, B. C. 2012. Enhancement of antimycotic activity of amphotericin B by targeting the oxidative stress response of Candida and Cryptococcus with natural dihydroxybenzaldehydes. Front. Microbiol. 3:261.

Kim, J. H., Campbell, B. C., Mahoney, N., Chan, K. L., Molyneux, R. J. and Xiao, C. L. 2010. Use of chemosensitization to overcome fludioxonil resistance in Penicillium expansum. Lett. Appl. Microbiol. 51:177-183.

Kogen, H., Tago, K., Kaneko, S., Hamano, K., Onodera, K., Haruyama, H., Minagawa, K., Kinoshita, T., Ishikawa, T., Tanimoto, T. and Tsujita, Y. 1996. Schizostatin, a novel squalene synthase inhibitor produced by the mushroom, Schizophyllum commune. II. Structure elucidation and total synthesis. J. Antibiot. 49:624-630.

Kuck, K.-H. 2007. QoI fungicides: resistance mechanisms and its practical importance. In: Pesticide chemistry: crop protection, public health, environmental safety, eds. by $\mathrm{H}$. Ohkawa, $\mathrm{H}$. Miyagawa and P. W. Lee, pp. 275-283. Wiley-VCH, Weinheim, Germany.

Leroux, P. 2007. Chemical control of Botrytis and its resistance to chemical fungicides. In: Botrytis: biology, pathology and control, eds. by Y. Elad, B. Williamson, P. Tudzynski and N. Delen, pp. 195-222. Springer, Dordrecht, Netherlands.

Liu, X., Jiang, J., Shao, J., Yin, Y. and Ma, Z. 2010. Gene transcription profiling of Fusarium graminearum treated with an azole fungicide tebuconazole. Appl. Microbiol. Biotechnol. 85:1105-1114.

Meletiadis, J., Mouton, J. W., Meis, J. F. M. and Verweij, P. E. 2003. In vitro drug interaction modeling of combinations of azoles with terbinafine against clinical Scedosporium prolifcans isolates. Antimicrob. Agents and Chemother. 47:106117.

Nyilasi, I., Kocsubé, S., Krizsán, K., Galgóczy, L., Pesti, M., Papp, T. and Vágvölgyi, C. 2010. In vitro synergistic interactions of the effects of various statins and azoles against some clinically important fungi. FEMS Microbiol. Lett. 307:175-
184.

Oliver, R. P. and Hewitt, H. G. 2014. Fungicides in crop protection. 2nd ed. CABI, Wallingford, UK. 190 pp.

OuYang, Q., Tao, N. and Jing, G. 2016. Transcriptional profiling analysis of Penicillium digitatum, the causal agent of citrus green mold, unravels an inhibited ergosterol biosynthesis pathway in response to citral. BMC Genomics 17:599.

Perea, S., Gonzalez, G., Fothergill, A. W., Sutton, D. A. and Rinaldi, M. G. 2002. In vitro activities of terbinafine in combination with fluconazole, itraconazole, voriconazole, and posaconazole against clinical isolates of Candida glabrata with decreased susceptibility to azoles. J. Clin. Microbiol. 40:1831-1833.

Rogers, P. D. and Barker, K. S. 2003. Genome-wide expression profile analysis reveals coordinately regulated genes associated with stepwise acquisition of azole resistance in Candida albicans clinical isolates. Antimicrob. Agents Chemother. 47:1220-1227.

Sharma, M., Manoharlal, R., Negi, A. S. and Prasad, R. 2010. Synergistic anticandidal activity of pure polyphenol curcumin I in combination with azoles and polyenes generates reactive oxygen species leading to apoptosis. FEMS Yeast Res. 10:570-578.

Sharma, M., Manoharlal, R., Shukla, S., Puri, N., Prasad, T., Ambudkar, S. V. and Prasad, R. 2009. Curcumin modulates efflux mediated by yeast ABC multidrug transporters and is synergistic with antifungals. Antimicrob. Agents Chemother. 53:3256-3265.

Sun, L., Sun, S., Cheng, A., Wu, X., Zhang, Y. and Lou, H. 2009. In vitro activities of retigeric acid $\mathrm{B}$ alone and in combination with azole antifungal agents against Candida albicans. Antimicrob. Agents Chemother. 53:1586-1591.

Tanaka, Y. and Omura, S. 1993. Agroactive compounds of microbial origin. Annu. Rev. Microbiol. 47:57-87.

Tanimoto, T., Onodera, K., Hosoya, T., Takamatsu, Y., Kinoshita, T., Tago, K., Kogen, H., Fujioka, T., Hamano, K. and Tsujita, Y. 1996. Schizostatin, a novel squalene synthase inhibitor produced by the mushroom, Schizophyllum commune. I. Taxonomy, fermentation, isolation, physico-chemical properties and biological activities. J. Antibiot. 49:617-623.

Zeun, R. and Buchenauer, H. 1991. Synergistic effects of pyrazophos and propiconazole against Pyrenophora teres. J. Plant Dis. Prot. 98:661-668 (in German).

Ziogas, B. N. and Malandrakis, A. A. 2015. Sterol biosynthesis inhibitors: C14 demethylation (DMIs). In: Fungicide resistance in plant pathogens, eds. by H. Ishii and D. W. Hollomon, pp. 199-216. Springer, Tokyo, Japan. 